\title{
ISOLASI DAN KARAKTERISASI SELULOSA : REVIEW
}

\author{
Irwan Mulyadi \\ Program Studi Teknik Kimia Fakultas Teknik UNPAM \\ irwanmulyadi12@gmail.com
}

\begin{abstract}
Cellulose, one of the most renewable natural resources in Indonesia. The presence of cellulose is inseparable from lignocellulose. Therefore, to get cellulose, it must be isolated from lignocellulose. This aim of this study to review the isolation and characterization of cellulose. Cellulose isolation can be done by acid hydolysis treatment method, alkaline hydrolysis, steam explosion and enzymatic. Characterization of isolation can used 4 characteristics, namely preliminary analysis, especially comparison of cellulose and lignin, FTIR analysis, thermal analysis, and surface morphology analysis
\end{abstract}

Keywords :cellulose, isolation, acid hydrolysis, base hydrolysis, steam explosion, enzymatic, characterization

\begin{abstract}
Abstrak
Selulosa, salah satu sumber daya alam terbaharukan yang melimpah di Indonesia. Keberadaan selulosa tidak terlepas dari lignoselulosa. Oleh karena it untuk mendapatkan selulosa harus dilakukan pengisolasian dari lignoselulosa tersebut. Penulisan ini bertujuan untuk mereview tentang isolasi dan karakterisasi selulosa tersebut. Isolasi selulosa dapat dilakukan dengan metode perlakuan hidolisis asam, hidrolisis basa, ledakan uap dan enzimatik. Karakterisasi isolasi dapt menggunakan 4 karakteristik yaitu analisis proxymate terutama kandingan selulosa dan lignin, analisis FTIR, analisis termal, dan analisis morfologi permukaan
\end{abstract}

Kata Kunci: Selulosa, isolasi, hidrolisis asam, hidrolisis basa, ledakan uap, enzimatik, karakterisasi

\section{PENDAHULUAN}

Selulosa, salah satu sumber daya alam terbarukan yang paling berlimpah di Indonesia dan merupakan komponen utama dari lignoselulosa dari dinding sel pada tanaman bersama dengan hemiselulosa, lignin, pektin,dan lilin. Lignoselulosa bisa didapatkan dari berbagai limbah pertanian seperti bagas tebu, jerami, ampas sagu dan kelapa sawit. Berdasarkan data BPS (2016), jumlah produksi gula, tepung sagu, padi, dan minyak goreng adalah 2,33 juta ton , 440,516 ton, 32,42 juta ton, dan 33,5 juta ton. Dari data produksi ini, terlihat bahwa limbah yang dihasilkan dari proses tersebut memiliki kapasitas yang besar. Limbah dengan kapasitas yang besar memiliki permasalahan tersendiri dalam penanganannya. Penanganan yang biasa dilakukan adalah menjadikannya sebagai pakan ternak. Peningkatan manfaat secara maksimal diperlukan agar limbah tersebut mempunyai nilai yang lebih tinggi. Salah satu kandungan dari limbah tersebut adalah selulosa yang sifatnya ramah lingkungan , biokompatibilitas, dan sangat cocok untuk derivatisasi kimia (Ekebafe et al., 2011). Oleh karena itu, isolasi selulosa dan karakterisasinya merupakan hal yang penting untuk di ketahui agar dapat mengetahui metode yang cocok untuk proses isolasi selulosa tersebut.

Berbagai kajian tentang isolasi selulosa dari limbah pertanian telah dilakukan oleh Sun et al (2004), Purwaningsih (2012) melalui perlakuan alkali dan asam, Jufrinaldi (2018) melalui perlakuan kombinasi likuifaksi, alkali dan asam, Xie et al (2016) melalui kombinasi liquifaksi, alkali dan klorit, Tibolla et al(2014) melalui proses enzimatik, Chirayil et al (2014) melalui proses ledakan uap. Masing dari metode tersebut mempunyai proses yang harus dikelahui langkahnya. Atas dasar inilah penulis mereview berbagai proses isolasi selulosa terhadap limbah pertanian di Indonesia khususnya berbasiskan lignoselulosa. 


\section{PEMBAHASAN}

\subsection{Selulosa}

Keberadaan selulosa dialam tidak dalam bentuk murni tetapi masih dalam bentuk lignoselulosa seperti terlihat pada gambar 1. Pada jaringan tumbuhan kayu, selulosa dapat ditemukan bersamaan dengan hemiselulosa, pati dan lignin. Gabungan antara selulosa, hemiselulosa, dan lignin disebut lignoselulosa (Rowell 2005). Dari gambar 1 terlihat bahwa keberadaan antara selulosa dan lignin terikat satu sama lain sehingga dibutuhkan metode tertentu untuk memisahkan antara selulosa dengan ligininnya.

Selulosa merupakan polimer alam yang paling melimpah, biokompatibel, dan ramah lingkungan karena mudah terdegradasi, tidak beracun, serta dapat diperbarui. Selulosa belakangan ini digunakan sebagai bahan baku alternatif dalam industri dan menyebabkan permintaan selulosa terus meningkat. Hal ini disebabkan oleh semakin berkurangnya cadangan bahan baku yang berasal dari sumber daya alam tak terbarukan. Meskipun demikian, selulosa masih belum dapat dimanfaatkan di berbagai bidang karena kesukaran dalam pemrosesan akibat adanya ikatan hidrogen intra- dan antarmolekul yang kuat pada struktur selulosa (Song et al. 2008). Struktur selulosa terlihat pada gambar 1

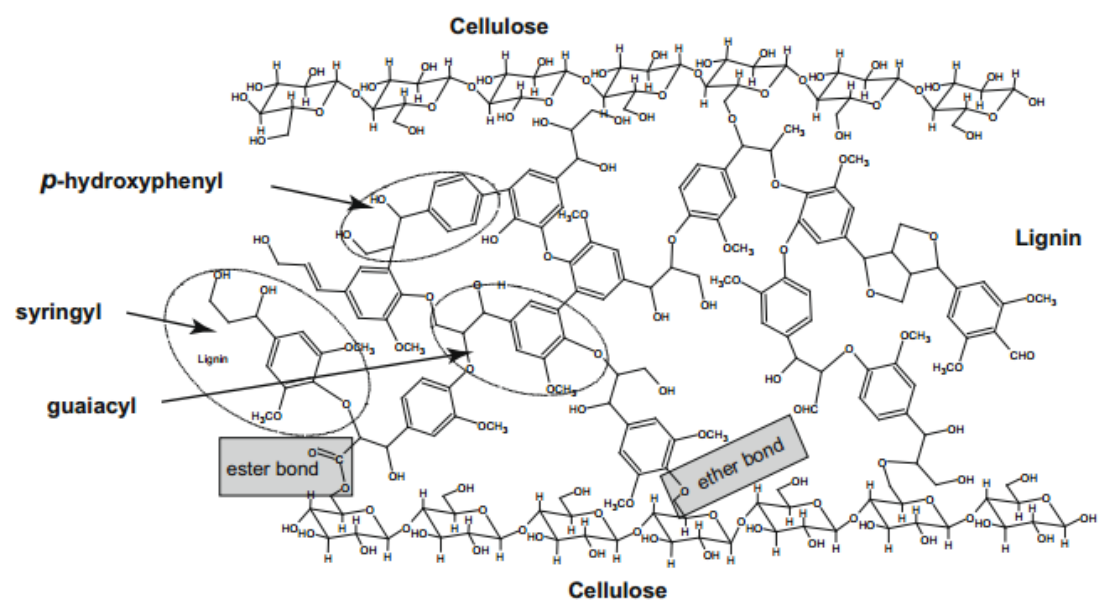

Gambar 1. Struktur lignoselulosa (zhou et al., 2010)

Selulosa termasuk polimer hidrofilik dengan tiga gugus hidroksil reaktif tiap unit hidroglukosa, tersusun atas ribuan gugus anhidroglukosa yang tersambung melalui ikatan 1,4- $\beta$-glukosida membentuk molekul berantai yang panjang dan linier. Gugus hidroksil ini telah dimanfaatkan untuk memodifikasi selulosa dengan memasukkan gugus fungsi tertentu pada selulosa melalui teknik pencangkokan (Klemm et. al., 1998). Gugus hidroksil pada C2 dan C3 adalah gugus hidroksil yang terikat pada atom karbon sekunder, sedangkan gugus hidroksil pada C6 terikat pada atom karbon primer. Kereaktifan dan kemasaman gugus hidroksil primer dan sekunder ini berbeda. .Dengan memilih monomer yang tepat, maka kekuatan mekanik dan stabilitas termal material berbasis selulosa yang dimodifikasi dengan teknik pencangkokan dapat ditingkatkan (Princi et al 2005). Struktur kimia dari monomer yang tercangkok ke selulosa akan mempengaruhi sifat dari selulosa tersebut. Reaktifitas selulosa dapat ditingkatkan melalui proses penggembungan selulosa. Penyerapan air atau pelarut tertentu dapat menyebabkan penggembungan selulosa Penggembungan selulosa merupakan tahapan yang diperlukan pada proses esterifikasi selulosa. Penggembungan selulosa dapat mempermudah pereaksi mencapai daerah kristalin. Kecepatan asetilasi pada selulosa yang telah mengalami pengembungan meningkat sekitar tiga kali lebih cepat daripada selulosa yang tidak mengalami penggembungan.

Berdasarkan derajat polimerisasi (DP) dan kelarutan dalam senyawa natrium hidroksida $(\mathrm{NaOH})$ $17,5 \%$, selulosa dapat dibagi atas tiga jenis (Nuringtyas, 2010), yaitu :

1) $\alpha$ - Selulosa (Alpha Cellulose) adalah selulosa berantai panjang, tidak larut dalam larutan $\mathrm{NaOH}$ $17,5 \%$ atau larutan basa kuat dengan DP (Derajat Polimerisasi) 600 - 15000. $\alpha$ - selulosa dipakai sebagai penduga dan atau tingkat kemurnian selulosa. Semakin tinggi kadar alfa selulosa, maka semakin baik mutu bahannya. 
2) Selulosa $\beta$ (Betha Cellulose) adalah selulosa berantai pendek, larut dalam larutan $\mathrm{NaOH} 17,5 \%$ atau basa kuat dengan DP (Derajat Polimerisasi) 15 - 90, dapat mengendap bila dinetralkan

3) Selulosa $\gamma$ (Gamma Cellulose) adalah selulosa berantai pendek, larut dalam larutan $\mathrm{NaOH} 17,5 \%$ atau basa kuat dengan DP (Derajat Polimerisasi) kurang dari 15, kandungan utamanya adalah hemiselulosa

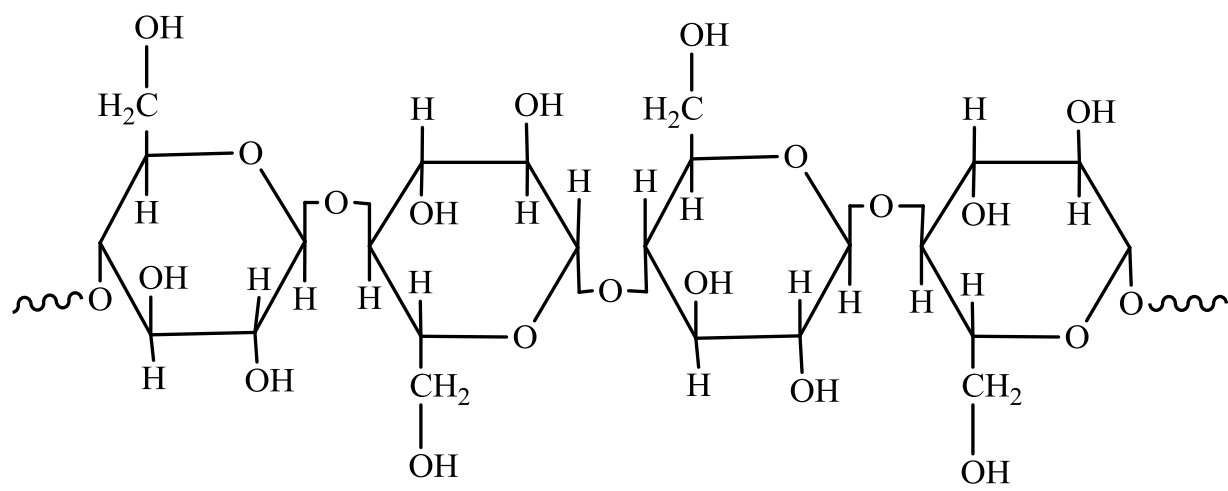

\subsection{Isolasi selulosa}

Gambar 2. Struktur selulosa

\subsubsection{Hidrolisis alkali}

Perlakuan hidrolisis alkali, metode yang paling umum digunakan untuk delignifikasi bahan lignoselulosa. Perlakuan ini dilakukan dengan tujuan mengganggu struktur lignin dan memungkinkan pemisahan hubungan struktural antara lignin dan selulosa (Zhou et al., 2010). Dalam perlakuan ini juga mengakibatkan putusnya ikatan pada rantai selulosa. Jufrinaldi (2018) melaporkan berhasil melakukan delignifikasi menggunakan pemanasan gelombang iradiasi mikro. Metode iradiasi gelombang mikro terbukti lebih effisien dan efektif dibandingkan dengan metode konvensional terutama dalam waktu proses. Perlakuan alkali biasanya dilkukan bersamaan dengan perlakuan asam. Metode ini merupakan proses yang sederhana, ekonomis dan ramah lingkungan. Namun, penting untuk diperhatikan bahwa proses ini perlu dikontrol dengan hati-hati untuk menghindari hal yang tidak diinginkan seperti degradasi selulosa.

\subsubsection{Hidrolisis asam}

Perlakuan hidrolisis asam, proses umum yang paling banyak digunakan karena membutuhkan waktu reaksi yang lebih pendek daripada proses lainnya. Asam bersenyawaan klorida, asam peroksida sering digunakan dalam perlakuan asam ini karena selain berfungsi sebagai delignifikasi juga berfungsi sebagai pemutih (Purwaningsih, 2012, Jufrinaldi, 2018). Putih yang dihasilkan menggunakan asam peroksida lebih gelap dibandingkan dengan asam berklorida tetapi dampak terhadap lingkungan dapat diminimalisasi apabila menggunakan asam peroksida. Selain senyawa asam tersebut, asam sulfat juga sering digunakan dalam perlakuan asam.

\subsubsection{Ledakan Uap}

Proses perlakuan ledakan uap telah diselidiki sebagai metode pulp mekanis yang menjanjikan karena menawarkan banyak hal menarik dibandingkan dengan teknologi lainseperti investasi modal lebih rendah, dampak lingkungan lebih rendah, lebih sedikit bahan kimia proses berbahaya dan kondisi dan lebih banyak potensi energi efisiensi (Pandey et al., 2015). Proses perlakuan ledakan uap dibagi ke dalam 2 tahap yaitu ekstraksi untuk pemulihan selulosa berderajta polimer rendah dan peresapan asam mineral kuat. Beberapa penulis melaporkan bahwa ledakan uap memungkinkan pemecahan bahan lignoselulosa komponen dengan pemanasan uap, gaya geser akibat ekspansi kelembaban dan hidrolisis ikatan glikosidik oleh asam organik yang terbentuk selama proses (Jacquet et al., 2015).

\subsubsection{Ekstrusi}

Teknologi ekstrusi adalah metode hidrolisis suhu tinggi dengan durasi pendek dengan keuntungan seperti fleksibilitas tinggi, proses yang ramah lingkungan dan tidak adanya efluen 
(Merci et al., 2015). Merci et al (2015) melaporkan metode ekstrusi dibagi menjadi 2 tahap yaitu ekstrusi dengan Ekstrusi basa Natrium Hidroksida dan Ekstrusi Asam Sulfat. Teknologi ekstrusi dapat dijalankan pada proses dengan kadar air lebih rendah.

\subsubsection{Enzimatik}

Teknologi enzimatik, teknologi terbaru yang digunakan dalam isolasi selulosa. Belum banyak peneliti melaporkan tentang isolasi tentang isolasi selulosa. Hal ini mungkin dikarenakan proses enzimatik lebih mahal dilihat dari nilai ekonomi tetapi mampu menghasilkan selulosa dengan kris kristalinitas lebih rendah (Hanna et al., 2001)

\subsection{Karakterisasi selulosa}

\subsubsection{Analisis proksimat}

Analisis komponen kimia pada isolat selulosa dari bagas tebu adalah salah satu indikator keberhasilan tahap isolasi. Evaluasi keberhasilan isolasi ditandai dengan peningkatan kadar $\alpha-$ selulosa, dan penurunan kadar ligninsecara signifikan. Berbagai kajian telah dilakukan untuk melakukan penurunan lignin hingga nol persen, tetapi sampai saat ini belum mampu pada target tersebut. Hal ini dikarenakan lignin dan selulosa mempunyai kemiripan sifat sehingga apabila ingin menhilangkan lignin maka akan terjadi pengurangan rendemen produk yang sangat besar. Dari beberapa penelitian terdahulu didapatkan sun et al (2004) sebesar 3,86\%, purwaningsih (2012) sebesar 0,96\% dan Jufrinaldi (2018) sebesar 1,65\%, Xie et al (2016) sebesar 0,13\%.

\subsubsection{Analisis FTIR ( Fourrier Transform Infrared)}

Spektroskopi FTIR adalah teknik yang sangat efektif dan cepat yang digunakan untuk mempelajari polimer. Pengukuran spektroskopi FTIR didasarkan pada intensitas dan panjang gelombang penyerapan radiasi Infrared yang mengakibatkan masing masing gugus fungsi bervibrasi pada bilangan gelombang khasnya. Di dalam spektrumnya, bilangan gelombang 4000$400 \mathrm{~cm}-1$ menjadi acuan utntuk melihat vibrasi molekul dari senyawa organik. Pada isolasi ini Spektroskopi FTIR diperlukan untuk menunjang dalam pengevaluasian keberhasilan selulosa dengan memantau pengurangan intensitas gugus fungsi molekul lignin dan peningkatan intensitas molekul selulosa (Jufrinaldi, 2018). Pengurangan intensitas gugus fungsi dapat dilihat pada bilangan gelombang $1700 \mathrm{~cm}-1$ yang menandakan adanya vibrasi karboksil lignin, $1500 \mathrm{~cm}-1$ yang menandakan adanya vibrasi guasil dan cincin lignin (Liu et al., 2006), $1240 \mathrm{~cm}-1$ yang menandakan adanya gugus siringil pada lignin (Paletto et al., 2014), $830 \mathrm{~cm}-1$ yang menandakan adanya OH tekuk gugus siringil (Zhang et al., 2010). Peningkatan intensitas molekul selulosa dapat terlihat pada bilangan gelombang $1200 \mathrm{~cm}-1$ yang menandakan gugus samping $\mathrm{OH}$ tekuk yang terikat pada cincin selulosa (Castro et al., 2011), $900 \mathrm{~cm}-1$ yang mengindikasikan adanya ikatan beta glikosida selulosa (Milovanovic et al., 2016)

\subsubsection{Analisis Termal}

Analisis termal digunakan untuk mengetahui sifat termal dan degradasi dari selulosa. Hal ini dapat dilakukan dengan thermogravimetric analysis (TGA), differential scanning calorimetry (DSC) dan differential thermal analysis (DTA). Secara umum kurva thermogram menunjukkan dua tahap yaitu dehidrasi dan degradasi. Pada tahap degradasi terjadi penurunan berat sampel karena adanya pelepasan air yang terjerap pada selulosa. Tahap ini terjadi pada kisaran suhu 60140 0C. Pada tahap berikutnya yaitu degradasi, terjadi proses dekarboksilasi, depolimerisasi dan dekomposisi unit glikosil selulosa serta pembentukan residu arang. Tahap ini terjadi pada kisaran suhu suhu 250-450 0C (Azubuike, 2012, Jufrinaldi, 2018, Karim et al., 2015, Purwaningsih, 2012). Analisis termal juga menunjukkan adanya puncak endotermik umum, yang sesuai dengan utama

dekomposisi karena volatilisasi selulosa menjadi levoglucosan dan charring (Trache et al., 2014). Menurut Adel dan El-Shinnawy (2012), degradasi selulosa berkontribusi pada evolusi senyawa volatil sementara degradasi lignin sesuai dengan sifat degradasi termal. Pada suhu lebih dari 450 0C akan menunjukkan ketidakteraturan pola dari kuva thermogram.

\subsubsection{Analisis morfologi permukaan}

Analisis morfologi permukaan sampel diperiksa secara luas menggunakan scanning electron microscope (SEM). Gambar yang terbentuk adalah dalam struktur tiga dimensi dan sangat berguna untuk menganalisis sampel karena menghasilkan gambar sampel dalam struktur 3 dimensi dan pembesaran dengan resolusi tinggi(Goldstein et al, 2012). Mikrograf selulosa yang 
diisolasi biasanya berbentuk serat. Penggumpalan serat selulosa sering terjadi sehingga ketika dilakukan analisis morfologi permukaan maka akan terlihat ukuran yang lebih besar.(Bhattacharya et al., 2008). Diameter selulosa berkisar antara 15-20 $\mu \mathrm{m}$, dengan panjang serat berkisar $100 \mu \mathrm{m}-1 \mathrm{~mm}$ (Elanthikal et al., 2010).

\section{KESIMPULAN DAN SARAN}

Isolasi selulosa dapat dilakukan dengan metode perlakuan hidolisis asam, hidrolisis basa, ledakan uap dan enzimatik. Karakterisasi isolasi dapt menggunakan 4 karakteristik yaitu analisis prksimat terutama kandingan selulosa dan lignin, analisis FTIR, analisis termal, dan analisis morfologi permukaan

\section{DAFTAR PUSTAKA}

Adel A M dan El-Shinnawy N A. 2012. Hypolipidemic applications of microcrystalline cellulose composite synthesized from different agricultural residues, Int. J. Biol. Macromol. 51(5) (2012) 1091-1102.

Azubuike C. 2012. Physicochemical, spectroscopic and thermal properties of powdered cellulose and microcrystalline cellulose derived from groundnut shells, J. Excipients Food Chem. 3(3) (2012) 106-115.

Bhattacharya D, Germinario LT, Winter WT. 2008. Isolation, preparation and characterization of cellulose microfibers obtained from bagasse. Carbohyd Polym. 73:371-377.

BPS. 2016. Statistik perkebunan Indonesia [Internet]. 2016 Desember: [diunduh 2019 februari 7]: Tangerang Selatan.

Castro C, Zuluaga R, Putaux JL, Caroa G, Mondragon I, Ganan P. 2011.Structural characterization of bacterial cellulose produced by gluconacetobacter swingsii sp from Colombian agroindustrial wastes. Carbohyd Polym. 84: 96-102

Chirayil CJ, Joy J, Mathew L, Mozetic M, Koetz, Thomsa S. 2014. Isolation and characterization of cellulose nanofibrils from helicteres isora plant. Indust Crops and Products. 59: 27-34.

Ekebafe LO, Ekebafe MO, Akpa FAO, Erhuanga G, Etiobhio BW. 2011. Graft copolymerization of acrylonitrile onto delignified native bamboo (Bambusa vulgaris) cellulosic and its utilization potential for heavy metal uptake from aqueous medium. CI \& CEQ. 17(2):133-140.

Elanthikal S, Gopala KU, Varghese S, Guthrie JI. 2010. Cellulose microfibres produces from banana plant wastes: Isolation and Characterization. Carbohyd Polym. 80:852-859.

J. Goldstein, D.E. Newbury, P. Echlin, D.C. Joy, A.D. Romig Jr, C.E. Lyman, C. Fiori, E. Lifshin, Scanning electron microscopy and X-ray microanalysis: a text for biologists, materials scientists, and geologists, Springer Science \& Business Media2012.

Hanna M, Biby G, Miladinov V. 2001. Production of microcrystalline cellulose by reactive extrusion, US Patent 6228213.

Jacquet N, Vanderghem, Danthine, Quievy N, Blecker C, Devaux J, Paquot M. 2012. Influence of steam explosion on physicochemical properties and hydrolysis rate of pure cellulose fibers, Bioresource Technol. 121 (2012) 221-227

Jufrinaldi. 2018. Isolasi selulosa dari bagas tebu melalui pemanasan iradiasi gelombang mikro. Jurn Ilmi Tek Kim UNPAM, Vol. 2 No. $2: 36$ - 46.

Karim M Z, Chowdhury Z Z, Hamid S B A, Ali M E. 2014. Statistical optimization for acid hydrolysis of microcrystalline cellulose and its physiochemical characterization by using metal ion catalyst, Materials 7(10) (2014) 6982-6999.

Klemm D, Philipp B, Heinze T, Heinze U, dan Wagenknecht W. 1998 Comprehensive Cellulose Chemistry:Fundamentals and Analytical Methods. Vol.1. Weiheim:Wiley-VCH Verlag GmBH. 
Liu CF, Ren JL, Xu F, Liu JJ, Sun JX, Sun RC. 2006. Isolation and characterization of cellulose obtain from ultrasonic irradiated sugarcane bagasse. Jour of Agric Food Chem. 54(16):5742-8

Merci A, Urbano A, Grossmann M V A, Tischer C A, Mali S. 2015. Properties of microcrystalline cellulose extracted from soybean hulls by reactive extrusion, Food Res. Int. 73 (2015) 38-43

Milovanovic S, Markovic D, Aksentijevic K, Stojanovic DB, Ivanovic J, Zizovic I. 2016. Application of cellulose acetate for controlled release of thymol. Carbohyd Polym. doi:10.1016/j.carbpol.2016.03.093

Nuringtyas, Tri Rini. 2010. Karbohidrat. Gajah Mada University Press, Yogyakarta.

Poletto M, Junior HLO, Zattera AJ. 2014. Native cellulose: structure, characterization and thermal properties. mater. 7: 6105-6119. Doi:10.3390/ ma7096105

Pandey J, Takagi H, Nakagaito A, Kim H. 2015.Handbook of polymer nanocomposites. Processing, performance and application, Springer.

Princi E, Vicini S, Proietti N, Capitani D. 2005. Grafting polymerization on cellulose based textiles: a 13C solid state NMR characterization. European Polymer Journal. 41:1196-1203.

Purwaningsih H. 2012. Rekayasa biopolimer dari limbah pertanian berbasis selulusa dan aplikasinya sebagai material separator [Disertasi]. Bogor (ID):Institut Pertanian Bogor.

Rowell, Roger M. 2005. Chemical modification of wood. Handbook of wood chemistry and wood composites. Boca Raton, Fla. : CRC Press, 2005: pages 381-420.

Song Y. Zhou J, Zhang L, Wu X. 2008. Homogenous modification of cellulose with acrylamide in $\mathrm{NaOH} /$ urea aqueous solutions. Carbohydrate Polymers 73:18-25.

Sun JX, Sun XF, Zhao H, Sun RC. 2004. Isolation and characterization of cellulose from sugarcane bagasse. Jour Polymer Degrab Stab. 84:331-339.

Tibolla H, Pelissari FM, Menegalli FC. 2014. Cellulose nanofibers produced from banana peel by chemical and enzymatic treatment. LWT-Food Scien and Tech. 59:1311-1318.

Trache D, Donnot A, Khimeche K, Benelmir R, Brosse N. 2014. Physico-chemical properties and thermal stability of microcrystalline cellulose isolated from Alfa fibres, Carbohyd. Polym. 104 (2014) 223-230.

Xie J X, Y un C Y, De Hoop C F, Hu T, Qi J, Shupe T F. 2016. Isolation and characterization of cellulose nanofibers from bamboo using microwave liquefaction combined with chemical treatment and ultrasonication. Carbohyd Polym. doi:10.1016/j.carbpol.2016.06.011, forthcoming.

Zhang M, Qi W, Liu R, Su R, Wu S, He Z. 2010. Fractionating lignocellulose by formic acid: characterization of major components. Biomass and Bioen. 34: 525-532.

Zhou Y, Stuart-Williams H, Farquhar GD, Hocart CH. 2010. The use of natural abundance stable isotopic ratio to indicate the presence of oxygen-containing chemical linkages between cellulose and lignin in plant cell walls. Phytochemistry 71:982-993. 